\title{
EFFECT OF SALINITY ON SEED GERMINATION AND SEEDLING CHARACTERS OF SOME FORAGE SORGHUM CULTIVARS
}

\author{
KANDIL A.A. ${ }^{1}$, SHARIEF A.E. ${ }^{*}{ }^{*}$, ABIDO W.A.E. ${ }^{1}$ AND IBRAHIM M.M. ${ }^{2}$ \\ 1Department of Agronomy, Faculty of Agriculture, Mansoura University, Egypt. \\ 2Ministry of Agriculture, Egypt. \\ *Corresponding Author: Email- shariefali42@gmail.com
}

Received: November 08, 2012; Accepted: November 23, 2012

\begin{abstract}
In order to investigate the effects of osmotic stress on forage sorghum varieties at critical stage of germination to salinity stress. A study was conducted at the Seed Technology Laboratory of Mansoura University, Egypt during April to June 2012. Three forage sorghum cultivars (Mabrouk, Horas, Pionner-8581) were evaluated in the salinity concentrations of 0, 2, 4, 6, 8, 10, 12, 14 and 16 $\mathrm{dSm}^{-1} \mathrm{NaCl}$. Four parameters namely final germination percentage, germination index, energy of germination and seedling vigour index were estimated. Eight seedling characters namely shoot and root length, shoot and root foliage weight, shoot and root dry weight, seedling height reduction and relative seedling dry weight were measured. Forage sorghum cultivars significantly varied in means of final germination percentage, germination index, seedling vigor index, energy of germination, shoot and root lengths, shoot and root fresh weights, shoot and root dry weights, seedling height reduction and relative dry weight. Horas cultivar surpassed other cultivars in all of the studied characters followed by Mabrouk cultivar which came in the second rank, while Pioneer 858 cultivar came in the last rank. Pioneer 858 cultivar recorded highest values of seedling height reduction and relative dry weight followed by Mabrouk cultivar, while, Horas cultivar came in the last rank for both characters. Increasing salinity levels from 0 to $15 \mathrm{dSm}^{-1}$ significantly decreased germination percentage, germination index, seedling vigor index, energy of germination, shoot and root lengths, shoot and root fresh weights, shoot and root dry weights and relative dry weight, the control treatment recorded the highest averages of these characters. Thus, the lowest averages of these characters were recorded with highest salinity levels i.e. $15 \mathrm{dSm}^{-1}$. Seedling height reduction percentage was increased significantly with increasing salinity levels from 0 to $15 \mathrm{dSm}^{-1}$. Results clearly showed that germination index, seedling vigor index, shoot and root lengths, shoot and root fresh weights, shoot and root dry weights, seedling height reduction and relative dry weight significantly affected by the interaction between forage sorghum cultivars and salinity concentrations. It could be concluded that Hoars cultivar was more tolerant to salinity stress followed by Mabrouk cultivars which must be put in breeding program of forage sorghum under salinity conditions.
\end{abstract}

Keywords- Forage sorghum cultivars, Germination parameters, Seedling characters, Salinity levels, seedling height reduction and relative dry weight.

Citation: Kandil A.A., et al. (2012) Effect of Salinity on Seed Germination and Seedling Characters of Some Forage Sorghum Cultivars. International Journal of Agriculture Sciences, ISSN: 0975-3710 \& E-ISSN: 0975-9107, Volume 4, Issue 7, pp-306-311.

Copyright: Copyright@2012 Kandil A.A., et al. This is an open-access article distributed under the terms of the Creative Commons Attribution License, which permits unrestricted use, distribution and reproduction in any medium, provided the original author and source are credited.

\section{Introduction}

Seed germination is one of the significant factor that process during the stages of forage sorghum life cycle in arid and semi-arid region [11]. Seed germination and early seedling growth are dangerous stage for the establishment of plant populations under saline conditions [18]. The salinity of water and soil is one of the stress factors, especially in the regions where irrigation is unavoidable [28]. Sorghum is appropriate for providing forage because of having high producing amount in the unit of level and the more efficiency of using water, the special morphology features of this plant leads to know that as index of crop resistance to drought [9]. In terms of salinity tolerance degree it also be known as a moder- ately tolerant crop with the almost salinity tolerance of $6.8 \mathrm{dSm}^{-1}$ [10]. But among varieties of one agricultural species, bearing of salinity factor can be very dissimilar. These differences in agricultural species can be important as an index for assessor salinity tolerance [12]. Seed with rapid germination under salt stress and normal conditions may be predictable to achieve a rapid seedling establishment and more salt tolerance [4]. Xiu-Ling W., et al [30] found that "Rio" and "Theis" cultivars are most salinity tolerant and "BJK236", "Mer-72-2" cultivars are most salinity sensitive among thirty-nine sweet sorghum varieties. Germination rate, germination index, germination energy, vigor index, root length and root fresh weight of sweet sorghum varieties under salt stress are significantly different from those under control. This cultivar was found to be the 
most tolerant cultivar. Whereas, Jitian2 cultivar was the least tolerant cultivar. Asfaw K.G. [2] indicated that accessions such as 235461, 69239, 223550, 69029 and 23403 were found to be salt tolerant, whereas, accessions 22885, 233247, 237264, 237265 and 237267 were found to be salt sensitive. El Naim A.M., et al [5] pointed out that the cultivar Wad Ahmed (V2) was found salt tolerant with respect to seedling biomass production. Kausar A., et al [16] showed that sorghum lines JS-2002 and Sandalbar were categorized as tolerant, Hegari- sorghum and JS-263 as medium tolerant while Noor as medium sensitive and FJ-115 and PSV-4 as sensitive ones. Rani C.R., et al [23] indicated that CSV-15 and HC171 cultivars showed the utmost shoot and root lengths, and total dry weight. They also showed that there is a substantial intraspecific variation in salinity tolerance.

Salt stress adversely affects plants at all stages of their life cycle. Salinity affects seed germination by creating an external osmotic potential that prevents water uptake or due to the toxic effects of sodium and chloride ions on the germinating seed [17]. Plants differ in their ability to develop under saline conditions [10]. Salinity compact root length and plant height as the level of salt increased, however, the decrease in the length of the roots was more prominent as compared to the shoots $[3,25]$. This decrease may be due to the toxic effect of $\mathrm{NaCl}$ as well as to an imbalance of nutrients in the plants. Low level of salinity $\left(2 \mathrm{dSm}^{-1}\right)$ augmented seed germination percentage, while the high levels $\left(4,8\right.$ and $\left.16 \mathrm{dSm}^{-1}\right)$ significantly inhibited seed germination and seedling growth i.e. shoot and root lengths and shoot and root fresh and dry weights and they added that the solidest inhibition of germination occurred at the higher salt concentrations $[3,5,23,26,29]$. Sadeghi $H$., et al [26] showed that aggregate salt concentrations reduced germination and seedling growth in all the cultivars and the extent of decrease varied with cultivars and salt concentrations. The presence of high salt concentration (10 and $12 \mathrm{EC}$ ), CSV-15 and HC-171 cultivars showed the utmost shoot and root lengths and total dry weight. The shoot growth of sorghum cultivar was more adversely affected compared to the root growth by salt stress. The specific objectives of this investigation were to compare tolerance levels of three forage sorghum to salinity as well as to determine the relative salinity, germination and seedling parameters responses of the forage sorghum varieties to different levels of salinity.

\section{Materials and Methods}

A laboratory experiment was carried out in Seed Science and Technology Laboratory, Agronomy Department, Faculty of Agriculture at Mansoura University during the period from April to Mai 2012. The aim of this investigation was study the response of some forage sorghum cultivars to germinate under salinity levels and to confirm the seedling growth performance for salinity tolerance among forage sorghum cultivars.

\section{Treatments and Experimental Design}

The experiment was arranged in factorial experiment in randomized complete block design (RCBD) with four replications. The experiment included two factors, the first factor included three different forage sorghum cultivars, which were obtained from department of Forage Crops, Agricultural Research Center, Ministry of Agriculture and Land Reclamations, Egypt i.e. Horas and Mabrouk The third cultivar Pioneer 858 cultivar was obtained from private seed company. All cultivars were stored under normal conditions in paper bags. The second factor included eight salt concentrations of $\mathrm{NaCl} \mathrm{dSm}{ }^{-1}$ includes $0,3,5,7,9,11,13$ and $15 \mathrm{dSm}^{-1} \mathrm{NaCl}$. Seeds of cultivars were surface sterilized by immersion for 5 minutes in sodium hypochlorite solution, then repeatedly washed with deionized water. Fifty seeds of uniform size in each treatment for each cultivar were allowed to germinate on a filter paper in $9 \mathrm{~cm}$ diameter Petri dishes. Each filter paper was moistened with a water solution at eight different $\mathrm{NaCl}$ concentrations. Thus, the whole experiment comprised 96 Petri dishes and Petri dishes were placed in a growth chamber for 12 days at $25 \pm 1^{\circ} \mathrm{C}$ for germination.

\section{Studied Characters}

After 12 days ten seedlings were selected from each replicates and then seedlings were evaluated as follows:

\section{A. Germination Parameters}

I. Final Germination Percentage (FGP): The number of seeds germinated at the end of experiment was considered and expressed as percentage as described in the following equation $[6,24]$ :

$$
(F G P)=\frac{\text { Number of germinated seeds after } 12 \text { days }}{\text { Number of seeds tested }} \times 100
$$

II. Germination Index (GI): It was calculated according to the following equation [15]:

$$
(\mathrm{GI})=\frac{\% \text { Germination in each treatment }}{\% \text { Germination in the control }}
$$

III. Seedling Vigor index (SVI): it was calculated using following equation [1]:

$(\mathrm{SVI})=($ Average shoot length + Average root length $) \times$ Germination percentage

IV. Energy of germination (EG): Energy of germination was recorded at the fourth day as the percentage of germinating seeds 4 days after sowing relative to the number of seeds tested [24].

\section{B. Seedling Characters}

I. Shoot length $(\mathrm{cm})$.

II. Root length (cm).

III. Shoot fresh weight $(\mathrm{g})$.

IV. Root fresh weight (g).

V. Shoot dry weight $(\mathrm{g})$.

VI. Root dry weight (g).

VII. Seedling height reduction (SHR): It was calculated using the following equation [14].

$\mathrm{SHR}(\%)=\frac{\text { Plant height at control }- \text { Plant height at saline condition }}{\text { Plant height at saline condition }} \times 100$

VIII.Relative dry weight (RDW): It was calculated according to the following equation [14]:

RDW $(\%)=\frac{\text { Total dry weight under saline condition }}{\text { Total dry weight under control condition }} \times 100$ 


\section{Statistical Analysis}

All data of this study were statistically analyzed according to the technique of variance (ANOVA) for factorial experiment in Randomized Complete Block Design (RCBD) as published by Gomez K.A., et al [8] by using means of "MSTAT-C" computer software package. Least Significant Differences (LSD) method was used to test the differences between treatment means at $5 \%$ and $1 \%$ levels of probability [27].

\section{Results and Discussion}

\section{Cultivars Performance}

Results presented in [Table-1], [Table-2], [Table-3] showed that forage sorghum cultivars a significantly affected final germination percentage (FGP), germination index (GI), seedling vigor index (SVI), energy of germination (EG), shoot and root lengths (cm), shoot and root fresh weights $(\mathrm{g})$, shoot and root dry weights $(\mathrm{g})$, seedling height reduction (SHR \%) and relative dry weight (RDW\%). Horas cultivar surpassed other cultivars in final germination percentage, germination index and seedling vigor index, energy of germination, shoot and root length $(\mathrm{cm})$, shoot and root fresh weight $(\mathrm{g})$, shoot and root dry weight $(\mathrm{g})$ followed by Mabrouk cultivar, which came in the second rank. While, Pioneer 858 cultivar recorded the lowest values of these characters. It can be noticed that Horas cultivar surpassed other cultivars in averages of FGP, GI, SVI, and EG by $41.67,22.40,56.17$ and $54.71 \%$, respectively than Pioneer 858 cultivar and by $12.8,8.23,18.23$ and $13.22 \%$, respectively compared with Mabrouk cultivar. Horas cultivar surpassed shoot and root length, shoot and root fresh weight, shoot and root dry weight, by $31.54,30.99,46.66,44.44,44.44$ and $33.33 \%$, respectively compared with Pioneer 858 cultivar and by $8.48,13.37,10,11.11,11.11$ and $0 \%$, respectively compared with Mabrouk cultivar.

Table 1- Means of final germination percentage (\%), germination index (\%), seedling vigor index and energy of germination as affected by forage sorghum cultivars and salinity concentrations

\begin{tabular}{|c|c|c|c|c|}
\hline Treatments & $\begin{array}{c}\text { Final germination } \\
\text { percentage }(\%)\end{array}$ & $\begin{array}{l}\text { Germination } \\
\text { Index (\%) }\end{array}$ & $\begin{array}{c}\text { Seedling } \\
\text { vigor index }\end{array}$ & $\begin{array}{l}\text { Energy of } \\
\text { germination }\end{array}$ \\
\hline \multicolumn{5}{|c|}{ Sorghum cultivars performance } \\
\hline Mabrouk & 71.31 & 77.46 & 901 & 60.12 \\
\hline Pioneer 858 & 47.75 & 65.5 & 483 & 31.37 \\
\hline Horas & 81.87 & 84.41 & 1102 & 69.28 \\
\hline F-Test & ** & ${ }^{\star *}$ & ** & ** \\
\hline L.S.D. $5 \%$ & 2.54 & 3.35 & 37 & 5.16 \\
\hline L.S.D. $1 \%$ & 3.38 & 4.45 & 50 & 4.75 \\
\hline \multicolumn{5}{|c|}{ Salinity concentrations effect } \\
\hline $0 \mathrm{dSm}^{-1} \mathrm{NaCl}$ & 87.33 & 100 & 1862 & 71.33 \\
\hline $3 \mathrm{dSm}^{-1} \mathrm{NaCl}$ & 79.33 & 90.37 & 1320 & 63.33 \\
\hline $5 \mathrm{dSm}^{-1} \mathrm{NaCl}$ & 74.33 & 84.17 & 1051 & 60 \\
\hline $7 \mathrm{dSm}{ }^{-1} \mathrm{NaCl}$ & 69 & 77.97 & 821 & 57.66 \\
\hline $9 \mathrm{dSm}{ }^{-1} \mathrm{NaCl}$ & 64 & 72.33 & 615 & 51 \\
\hline $11 \mathrm{dSm}^{-1} \mathrm{NaCl}$ & 59.33 & 66.76 & 487 & 45.75 \\
\hline $13 \mathrm{dSm}-1 \mathrm{NaCl}$ & 53.83 & 60.36 & 324 & 41.66 \\
\hline $15 \mathrm{dSm}^{-1} \mathrm{NaCl}$ & 48.66 & 54.37 & 151 & 38 \\
\hline F-Test & ${ }^{* *}$ & ${ }^{* *}$ & ${ }^{* *}$ & ** \\
\hline L.S.D. $5 \%$ & 4.15 & 5.47 & 61 & 5.84 \\
\hline L.S.D. $1 \%$ & 5.52 & 7.27 & 81 & 7.77 \\
\hline C-Interaction F-Test & NS & $\star \star *$ & ** & NS \\
\hline
\end{tabular}

*, ${ }^{* *}$ and NS mean significant and insignificant respectively at levels of probability 0.05 and 0.01 .
Table 2- Means of shoot length, root length, shoot fresh weight and root fresh weight as affected by forage sorghum cultivars and salinity concentrations

\begin{tabular}{|c|c|c|c|c|}
\hline Treatments & $\begin{array}{l}\text { Shoot length } \\
(\mathrm{Cm})\end{array}$ & $\begin{array}{l}\text { Root length } \\
(\mathrm{Cm})\end{array}$ & $\begin{array}{l}\text { Shoot fresh } \\
\text { weight (g) }\end{array}$ & $\begin{array}{l}\text { Root fresh } \\
\text { weight (g) }\end{array}$ \\
\hline \multicolumn{5}{|c|}{ Sorghum cultivars performance } \\
\hline Mabrouk & 6.15 & 5.31 & 0.027 & 0.024 \\
\hline Pioneer 858 & 4.6 & 4.23 & 0.016 & 0.015 \\
\hline Horas & 6.72 & 6.13 & 0.03 & 0.027 \\
\hline F-Test & $* *$ & $* *$ & $\star *$ & ** \\
\hline L.S.D. $5 \%$ & 0.21 & 0.21 & 0.001 & 0.001 \\
\hline L.S.D. $1 \%$ & 0.28 & 0.29 & 0.002 & 0.002 \\
\hline \multicolumn{5}{|c|}{ Salinity concentrations effect } \\
\hline $0 \mathrm{dSm}^{-1} \mathrm{NaCl}$ & 10.96 & 0.07 & 0.064 & 0.06 \\
\hline $3 \mathrm{dSm}^{-1} \mathrm{NaCl}$ & 8.49 & 7.99 & 0.042 & 0.03 \\
\hline $5 \mathrm{dSm}^{-1} \mathrm{NaCl}$ & 7.19 & 6.7 & 0.03 & 0.02 \\
\hline $7 \mathrm{dSm}{ }^{-1} \mathrm{NaCl}$ & 6.01 & 5.52 & 0.02 & 0.01 \\
\hline $9 \mathrm{dSm}^{-1} \mathrm{NaCl}$ & 5.09 & 4.44 & 0.015 & 0.01 \\
\hline $11 \mathrm{dSm}^{-1} \mathrm{NaCl}$ & 4.15 & 3.51 & 0.011 & 0.01 \\
\hline $13 \mathrm{dSm}{ }^{-1} \mathrm{NaCl}$ & 3.02 & 2.44 & 0.008 & 0.007 \\
\hline $15 \mathrm{dSm}^{-1} \mathrm{NaCl}$ & 1.69 & 1.1 & 0.003 & 0.003 \\
\hline F-Test & $\star *$ & $* *$ & ** & $\star *$ \\
\hline L.S.D. $5 \%$ & 0.34 & 0.35 & 0.002 & 0.002 \\
\hline L.S.D. $1 \%$ & 0.46 & 0.47 & 0.003 & 0.003 \\
\hline C-Interaction F-Test & $* *$ & $* *$ & ** & $* *$ \\
\hline
\end{tabular}

${ }^{*},{ }^{* *}$ and NS mean significant and insignificant respectively at levels of probability 0.05 and 0.01 .

Table 3- Means of shoot dry weight, root dry weight, seedling height reduction (SHR) and relative dry weight (RDW) as affected by forage sorghum cultivars and salinity concentrations.

\begin{tabular}{|c|c|c|c|c|}
\hline Treatments & $\begin{array}{l}\text { Shoot dry } \\
\text { weight (g) }\end{array}$ & $\begin{array}{l}\text { Root dry } \\
\text { weight (g) }\end{array}$ & $\begin{array}{l}\text { Seedling height } \\
\text { reduction }\end{array}$ & $\begin{array}{l}\text { Relative dry } \\
\text { weight }\end{array}$ \\
\hline \multicolumn{5}{|c|}{ Sorghum cultivars performance } \\
\hline Mabrouk & 0.008 & 0.012 & 47.84 & 31.78 \\
\hline Pioneer 858 & 0.005 & 0.008 & 48.87 & 35.71 \\
\hline Horas & 0.009 & 0.012 & 44.12 & 31.84 \\
\hline F-Test & ** & ** & ** & ** \\
\hline L.S.D. $5 \%$ & 0 & 0.002 & 1.86 & 2.61 \\
\hline L.S.D. $1 \%$ & 0.001 & 0.003 & 2.48 & 3.48 \\
\hline \multicolumn{5}{|c|}{ Salinity concentrations effect } \\
\hline $0 \mathrm{dSm}^{-1} \mathrm{NaCl}$ & 0.02 & 0.03 & 0 & 100 \\
\hline $3 \mathrm{dSm}^{-1} \mathrm{NaCl}$ & 0.01 & 0.01 & 21.83 & 57.41 \\
\hline $5 \mathrm{dSm}^{-1} \mathrm{NaCl}$ & 0.007 & 0.01 & 34.08 & 37.33 \\
\hline $7 \mathrm{dSm}^{-1} \mathrm{NaCl}$ & 0.005 & 0.007 & 45.25 & 23.5 \\
\hline $9 \mathrm{dSm}^{-1} \mathrm{NaCl}$ & 0.005 & 0.005 & 54.25 & 18.33 \\
\hline $11 \mathrm{dSm}^{-1} \mathrm{NaCl}$ & 0.003 & 0.004 & 62.5 & 14.41 \\
\hline $13 \mathrm{dSm}{ }^{-1} \mathrm{NaCl}$ & 0.002 & 0.003 & 72.91 & 9.25 \\
\hline $15 \mathrm{dSm}^{-1} \mathrm{NaCl}$ & 0.002 & 0.006 & 84.75 & 4.66 \\
\hline F-Test & ** & ** & ** & $* *$ \\
\hline L.S.D. $5 \%$ & 0.001 & 0.004 & 3.05 & 4.27 \\
\hline L.S.D. $1 \%$ & 0.001 & 0.006 & 4.05 & 5.69 \\
\hline C-Interaction F-Test & $* *$ & * & ** & $\star *$ \\
\hline
\end{tabular}

*, ** and NS mean significant and insignificant respectively at levels of probability 0.05 and 0.01 .

Results in [Table-3] clearly showed that highest averages of seedling height reduction and relative dry weight were produced from Pioneer 858 cultivar followed by Mabrouk cultivar which came in the second rank. While, the lowest values of these characters were produced from Horas cultivar. It could be stated that Pioneer 858 cultivar surpassed in seedling height reduction by $9.71 \%$ than Horas cultivar and by $2.10 \%$ compared with Mabrouk cultivar and surpassed in relative dry weight by $11 \%$ compared with Mabrouk 
cultivar and by $10.83 \%$ compared with Horas cultivar. The presence of broad intraspecific genetic variation among sorghum accessions for salt tolerance [7]. Salinity reduced germination parameters as the salt level was increased. The toxic effects of $\mathrm{Na}^{+}$and $\mathrm{Cl}$ ions on germinating seeds affect germination percentage, germination rate, energy of germination and seedling vigour index. Salinity exerts its undesirable effects through osmotic inhibition and ionic toxicity [21]. There are reports of genetic diversity in response to osmotic stress in a wide variety of plant species, which seems at variance with a central tenet of the two-phase hypothesis of salinity resistance [20]. The differences in germination parameters due to forage sorghum cultivars may be due the genetical factors and heredity variation among the three forage sorghum cultivars. These results are in good accordance with those obtained by $[2,5,16,30]$.

\section{Salinity Concentrations Effect}

Results in [Table-1], [Table-2], [Table-3] reported that salinity concentrations had a significant effect on averages of FGP, GI, SVI, $E G$, shoot and root length, shoot and root fresh weight, shoot and root dry weight, seeding height reduction and relative dry weight. Increasing salinity levels from 0 to $15 \mathrm{dSm}^{-1}$ significantly decreased all these character. Vice versa, seedling height reduction was increased with increasing of salinity concentrations. Results in Table 3 through 5 clearly showed that increasing salinity levels from 0 to $15 \mathrm{dSm}^{-1} \mathrm{NaCl}$ significantly reduced FGP, GI by (9.16 and $\left.9.63 \%\right)$, (14.88 and 15.83\%), (20.98 and 22.03\%), (26.71 and 27.67\%), (32.06 and $33.24 \%),(38.36$ and $39.64 \%)$ and $(44.28$ and $45.63 \%)$, respectively as the salinity levels order compared with the control treatment. While increasing salinity levels from 0 to $15 \mathrm{dSm}^{-1} \mathrm{NaCl}$ reduced SVI and EG by (29.10 and $11.21 \%)$, (43.55 and $15.88 \%)$, (55.90 and $19.16 \%)$, (66.97 and $28.50 \%)$, (73.84 and $35.86 \%)$, ( 82.55 and $41.59 \%)$ and $(91.89$ and $46.72 \%)$, respectively as the salinity levels order compared with the control treatment for both characters, respectively. Moreover, increasing salinity levels from 0 to $15 \mathrm{dSm}^{-1} \mathrm{NaCl}$ reduced shoot and root length by $(22.53$ and $20.65 \%)$, (34.39 and $33.46 \%)$, (45.16 and $45.18 \%)$, (53.55 and $55.90 \%),(62.13$ and $65.14 \%),(72.44$ and $75.76 \%)$ and (84.58 and $89.07 \%$ ), respectively as the salinity levels order compared with the control treatment. In addition, increasing salinity levels from 0 to 15 $\mathrm{dSm}^{-1} \mathrm{NaCl}$ reduced shoot and root fresh weight, shoot and root dry weight by $(34.37,50.0,50.0$ and $66.66 \%),(53.12,66.66,65.0$ and $66.66 \%),(68.75,83.33,75.0$ and $67.66 \%),(76.56,83.33,75.0$ and $83.33 \%)$, (82.81, 83.33, 85.0 and $86.66 \%),(87.50,88.33,90.0$ and $90.0 \%$ ) and $(95.31,95.0,90.0$ and $80.0 \%)$, respectively as the salinity levels order compared with the control treatment in each of the mentioned characters. Results revealed that increasing salinity levels from 0 to $15 \mathrm{dSm}^{-1} \mathrm{NaCl}$ reduced relative dry weights by $42.59,62.67,76.50,81.67,85.59,90.75$ and $95.34 \%$, respectively as the salinity levels order compared with the control treatment. Increasing salinity levels from 0 to $15 \mathrm{dSm}^{-1} \mathrm{NaCl}$ increased seedling height reductions by $56.11,107.88,148.51,186.30,233.98$ and 288.22 , respectively as the order of salinity levels compared with the control treatment. Plant for resistance against salinity increasing of proline, sugar and chlorophyll content in leaves are useful for retaining and improving of photosynthesis quality in plants [22]. Increasing salinity levels decreased germination parameter and seedling growth which is directly related to the amount of absorbed water by the seeds and the toxic effects of $\mathrm{Na}^{+}$at high salt concentrations might have caused physical damage to roots thereby decreasing their ability to absorb water and nutrient, which may resulted in poor growth [13]. Increment in salinity level caused reduction in final germination percentage FGP in most sorghum cultivars. Likewise, highest salinity levels had delayed germination (increased days of emergence). The delay was pronounced in saltsensitive accessions than in the intermediate and salt-tolerant ones which is in agreement with previous findings in sorghum [19]. These results are in agreement with those obtained by $[3,5,23,25,26]$.

\section{Interaction Effects}

Regarding to the interaction effects data illustrated in [Fig-1], [Fig2], [Fig-3], [Fig-4], [Fig-5], [Fig-6], [Fig-7], [Fig-8], [Fig-9], [Fig-10] clearly showed that $\mathrm{GI}, \mathrm{SVI}$, shoot and root length $(\mathrm{cm})$, shoot and root fresh weight $(\mathrm{g})$, shoot and root dry weight $(\mathrm{g})$, SHR \% and RDW \% were significantly affected by the interaction between forage sorghum cultivars and salinity concentrations. Vice versa, averages of FGP and EG did not reach the levels of significant. Results clearly indicated that highest percentages of $\mathrm{GI}$ was produced from the control treatment in all cultivars. While, the lowest percentages of germination index was produced from the salinity level of $15 \mathrm{dSm}^{-1} \mathrm{NaCl}$ with sown Pioneer 858 cultivar [Fig-1]. Highest seedling vigour index was produced from the control treatment, with sown Horas cultivar followed by the control treatment with Mabrouk cultivar without significant differences between them. While, the lowest values of seedling vigour index was produced from the salinity level of 13 or $15 \mathrm{dSm}^{-1} \mathrm{NaCl}$ with sown Pioneer 858 without significant differences between them [Fig-2]. In addition, sown Mabrouk cultivar and treated with highest salinity level of $15 \mathrm{dSm}^{-1} \mathrm{NaCl}$ also recorded the lowest values of seedling vigour index [Fig-3]. Horas cultivar surpassed in germination index, seedling vigour index, shoot and root length and shoot and root fresh weight under all salinity levels than the other two cultivars. Moreover, Mabrouk and Horas cultivars surpassed in root length under all salinity levels Pioneer 858 cultivar without significant differences between them [Fig-4], [Fig-5], [Fig-6], [Fig-7], [Fig-8], [Fig-9]. Increasing salinity concentrations to $15 \mathrm{dSm}^{-1} \mathrm{NaCl}$ and sown Pioneer 858 or Mabrouk cultivars significantly produced highest percentages of seedling height reduction as illustrated in [Fig-10] and lowest percentages of seedling height reduction without significant differences between them. These results are in good accordance with those obtained by $[3,5,23,26,29]$.

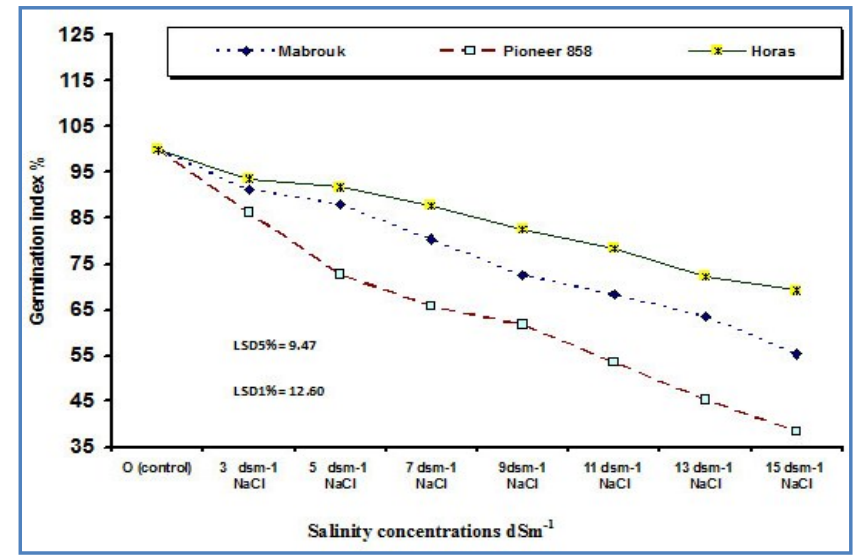

Fig. 1- Means of germination index as affected by the interaction between cultivars and salinity concentrations 


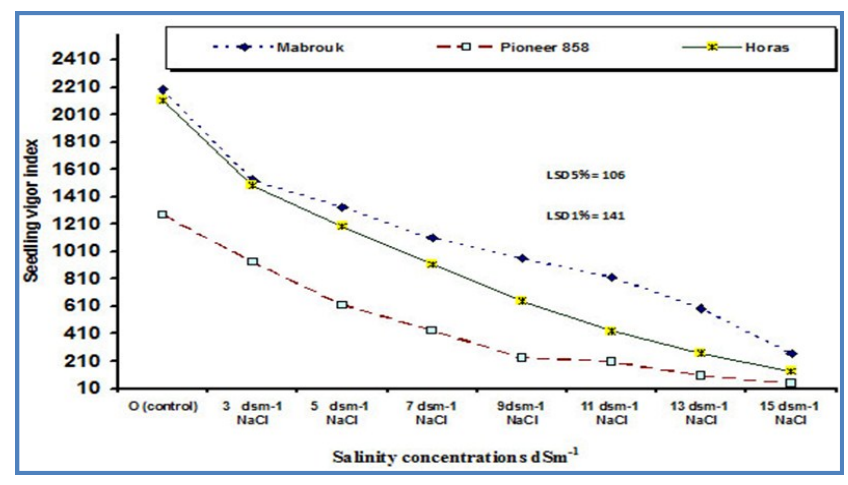

Fig. 2- Means of seedling vigor as affected by the interaction between cultivars and salinity concentrations

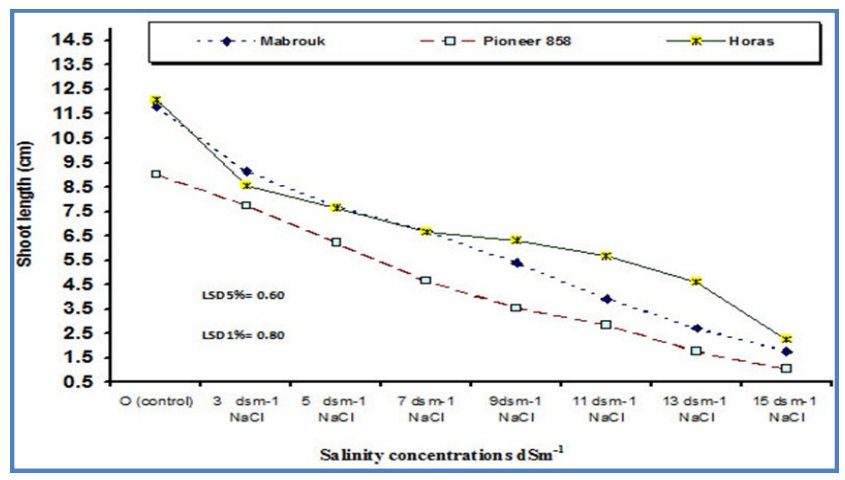

Fig. 3- Means of shoot length as affected by the interaction between cultivars and salinity concentrations

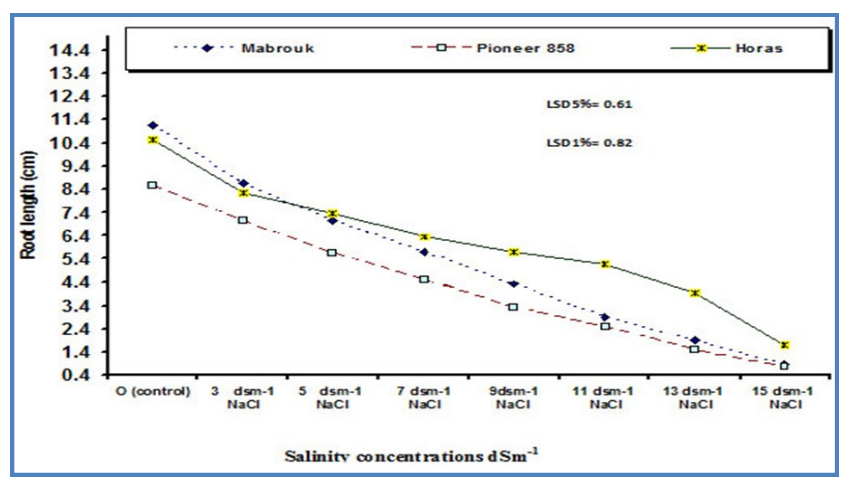

Fig. 4- Means of germination index as affected by the interaction between cultivars and salinity concentrations

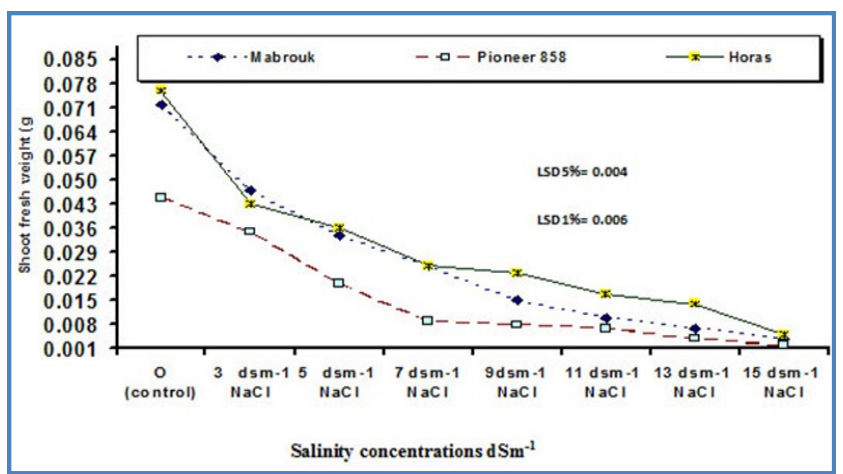

Fig. 5- Means of shoot fresh weight as affected by the interaction between cultivars and salinity concentrations

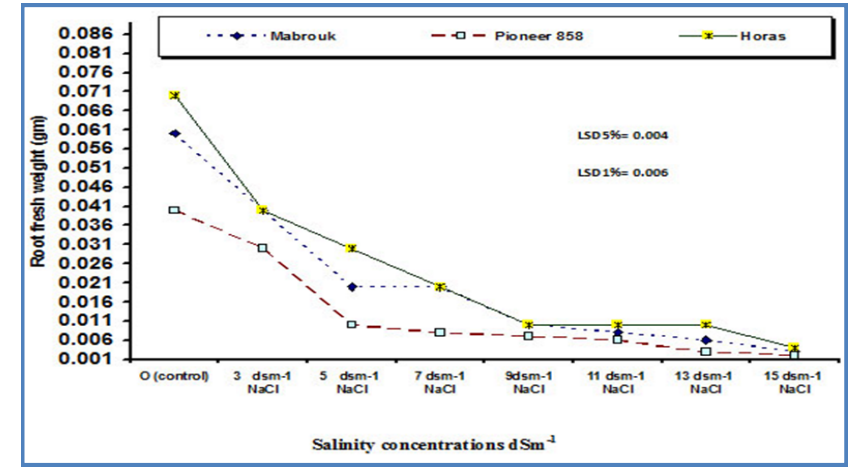

Fig. 6- Means of root fresh weight as affected by the interaction between cultivars and salinity concentrations

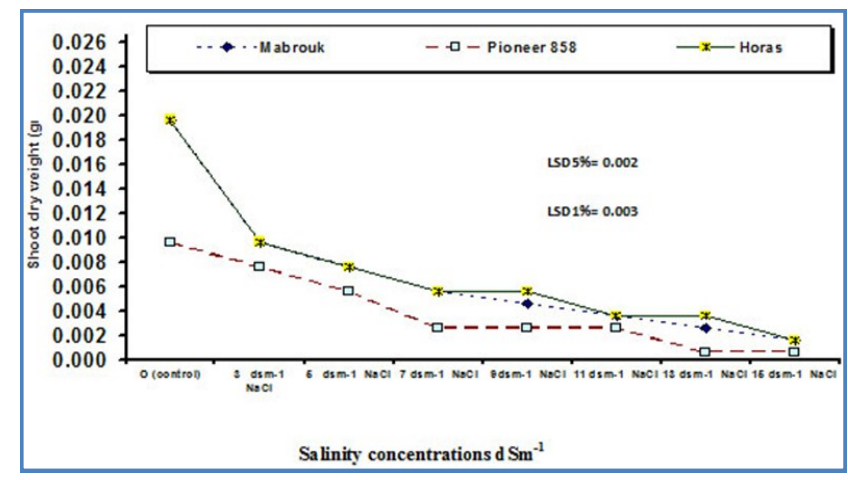

Fig. 7- Means of shoot dry weight as affected by the interaction between cultivars and salinity concentrations

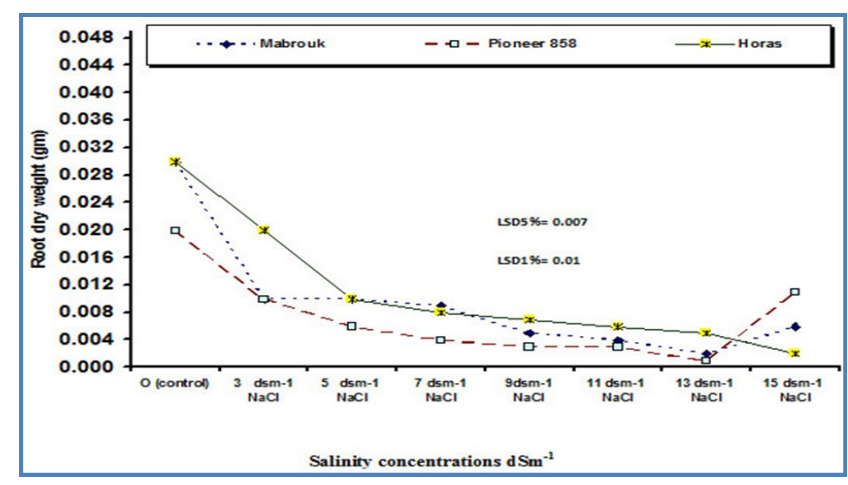

Fig. 8- Means of root dry weight as affected by the interaction between cultivars and salinity concentrations

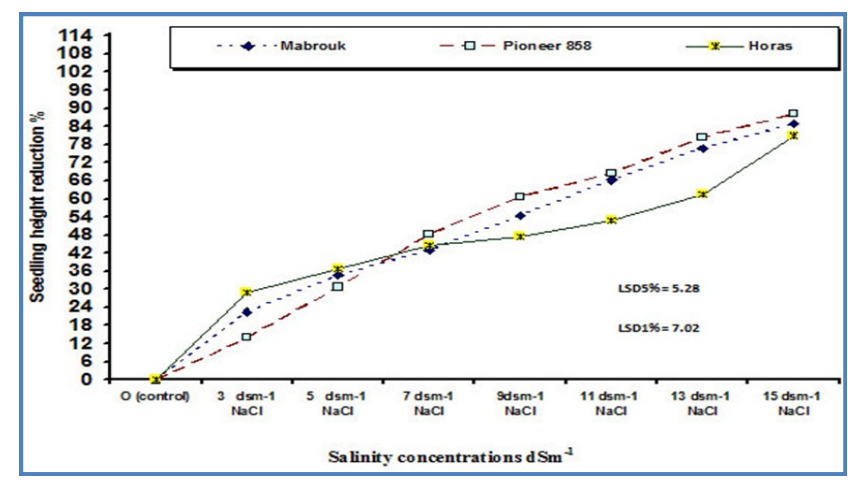

Fig. 9- Means of seedling height reduction as affected by the interaction between cultivars and salinity concentrations 


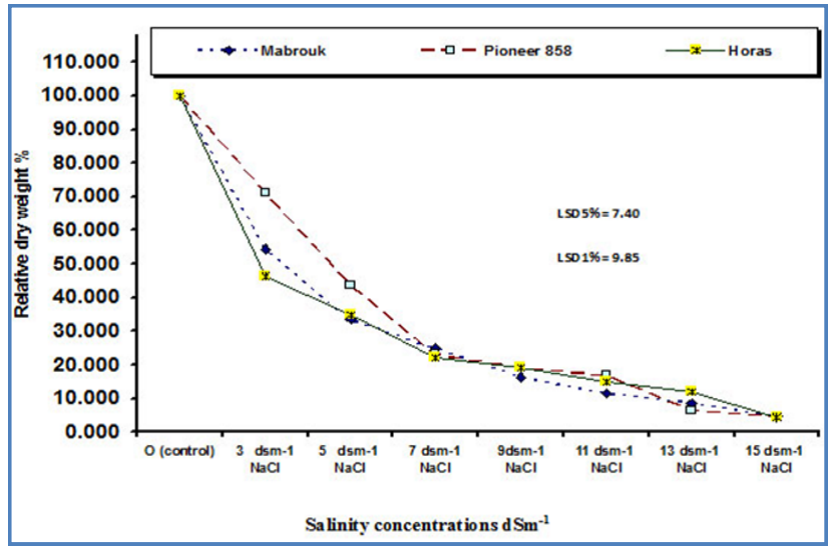

Fig. 10- Means of relative dry weight $\%$ as affected by the interaction between cultivars and salinity concentrations

\section{Conclusion}

It could be concluded that increasing salinity is associated with decreases in all the studied characters, germination or seedling parameters. To maximize forage sorghum germination percentage and seedling parameters under salinity stress, confirm achieving by using Horas cultivar due to its tolerance to high salinity concentrations and surpassing other cultivars in giving highest values of all the studied characters. This cultivar was more tolerant to salinity up to $15 \mathrm{dSm}^{-1} \mathrm{NaCl}$ and is proved to limit or reduce salinity effects on germination or growth of forage sorghums. Thus, it is recommended to use Horas cultivar in breeding programs for enhancing forage sorghum production in Egypt under saline conditions.

\section{References}

[1] Abdul-Baki A.A. and Anderson J.D. (1973) Crop Sci., 13, 630633.

[2] Asfaw K.G. (2011) Asian Journal of Agri. Sci., 3(3), 242-249.

[3] Bashir F., Ali M., Hussain K., Abdul Majeed and Nawaz K. (2011) Bot. Res. Intl., 4(1), 1-3.

[4] Bybordi A. and Tabatabaei J. (2009) Notulae Botanicae Horti Agrobotanici Cluj-Napoca, 37(2), 71-76.

[5] El Naim A.M., Mohammed K.E., Ibrahim E.A. and Suleiman N.N. (2012) Sci. and Techno., 2(2), 16-20.

[6] Ellis R.A. and Roberts E.H. (1981) Seed Sci. Technol., 9, 373409.

[7] Geressu K. and Gezaghegne M. (2008) African Journal of Agricultural Research, 3(1), 044-048.

[8] Gomez K.A. and Gomez A.A. (1984) Statistical Procedures in Agricultural Research, Wiley, 2nd ed., New York, 680.

[9] Gossett D.R., Millhollon E.P., Lucas M.C. (1994) Crop Sci., 34, 706-714

[10]Greenway H. and Munns R. (1980) Ann. Rev. Plant. Physiol., 31, 149-190.

[11]Hadas A. (2004) Handbook of Seed Physiology: Application to Agriculture, Food Product Press, New York, 3-49.

[12]Hollington P.A. (1998) Salinity Management in Agriculture, 273289. [13]lqbal A., Bakht J. and Shafi M. (2000) Pakistan J. Biol. Sci., 3 (9), 1406-1408.

[14]Islam M.M. and Karim M.A. (2010) The Agriculturists, 8(2), 5765.

[15]Karim M.A., Utsunomiya N. and Shigenaga S. (1992) Japanese J. of Crop Sci., 61, 279-284.

[16]Kausar A., Ashraf M.Y., Ali I., Niaz M. and Abbass Q. (2012) Pak. J. Bot., 44(1), 47-52.

[17]Khajeh-Hosseni M., Powell A.A. and Bingham I.J. (2003) Seed Sci. Tech., 31(3), 715-725.

[18]Khan M.A. and Gulzar S. (2003) J. Arid Environment, 53, 387394.

[19]Marambe B. and Ando T. (1995) J. Agronomy and Crop. Sci., $174,291-296$

[20]Munns R., Schachtman D.P. and Condon A.G. (1995) Australian Journal of Plant Physiology, 22, 561-569.

[21]Munns R., James R.A. and Lauchli A. (2006) J. Exp. Bot., 57, 1025.

[22]Rahdari P., Tavakoli S. and Hosseini S.M. (2012) Journal of Stress Physiology \& Biochemistry, 8(1), 182-193.

[23]Rani C.R., Reema C., Alka S. and Singh P.K. (2012) Res. J. Recent Sci., 1(3), 1-10.

[24]Ruan S., Xue Q. and Tylkowska K. (2002) Seed Science \& Techno., 30, 61-67.

[25]Saberi A.R., Siti Aishah H., Halim R.A. and Zaharah A.R. (2011) African J. of Biotechnology, 10(47), 9647-9656.

[26]Sadeghi H. and Shourijeh F.A. (2012) Asian J. of Plant Sci., 11 (1), 19-27.

[27]Snedecor G.W. and Cochran W.G. (1980) Statistical Methods, 7th Ed., 507.

[28]Tabatabaei S.A., Ranjbar G.H. and Anagholi A. (2012) International Research Journal of Applied and Basic Sciences, 3(2), 305-308.

[29]Wambua J.M., Makobe M.N., Njue E.M. and Nyende A.B. (2010) JAGST., 12(2), 82-91.

[30]Xiu-Ling W., Xu C. and Gui-Ying L. (2010) Chinese J. of EcoAgric., 18(6), 1239-1244. 